\title{
STUDY OF WOUND-DRESSING MATERIALS BASED ON COLLAGEN, SODIUM CARBOXYMETHYLCELLULOSE AND SILVER NANOPARTICLES USED FOR THEIR ANTIBACTERIAL ACTIVITY IN BURN INJURIES
}

\author{
SORINA-ALEXANDRA LEAU ${ }^{1}$, ŞTEFANIA MARIN ${ }^{2,3}$, GHEORGHE COAR $\breve{A}^{3}$, \\ LUMINIŢA ALBU ${ }^{3}$, RODICA ROXANA CONSTANTINESCU ${ }^{3}$, \\ MĂDĂLINA ALBU KAYA ${ }^{3}$, IONELA-ANDREEA NEACŞU ${ }^{4}$ \\ ${ }^{1}$ University Politehnica of Bucharest, Faculty of Medical Engineering, 1-7 Gheorghe Polizu Str., \\ 011061, Bucharest, Romania \\ ${ }^{2}$ University Politehnica of Bucharest, Center of Surface Science and Nanotechnology, Splaiul \\ Independentei 313, Romania \\ ${ }^{3}$ INCDTP - Division: Leather and Footwear Research Institute, 93 Ion Minulescu Str., 011061, \\ Bucharest, Romania \\ ${ }^{4}$ University Politehnica of Bucharest, Science and Engineering of Oxide Materials and \\ Nanomaterials Department, Splaiul Independentei nr.313, 060042, Bucharest, Romania
}

\begin{abstract}
There are 2 types of bacteria that can produce serious infections and in many cases they lead to intestinal infections, meningitis or even toxic shock syndrome: Escherichia coli (E.coli) and Staphyloccocus aureus (S.aureus). They are the most common source of infection worldwide and it's really necessary to understand their mecanism of action. The objective of this study was to develop and characterize wound-dressing materials based on collagen (COLL), sodium carboxymethylcellulose (CMC-Na) and silver nanoparticles (AgNPs) designed to be used for burn injuries. We chose to use a composite material because it has multiple desirable effects, both on the wound and against the bacteria. Type I fibrillar collagen gel was extracted from calf hide. Sodium carboxymethylcellulose was used because it's biocompatible and non-toxic. Silver nanoparticles were used for their antimicrobial activity. Obtained wound-dressing material was characterized by FT-IR spectroscopy, scanning electronic microscopy, water up-take and degradation in collagenase solution. The results showed that this combination of materials is ideal for a faster healing of the wound and it considerably reduces the risk of infection.
\end{abstract}

Keywords: collagen, carboxymethylcellulose, silver nanoparticles (AgNPs).

\section{INTRODUCTION}

Burns are tissue lesions produced by radiation exposure, thermal, chemical or electric agents (Herndon, 2012). Destruction of the skin protective barrier can lead to infections because the surface of the wound contains necrotic tissue and it's a suitable area for the adherence of bacteria (Deirdre, 2006). There are 2 types of bacteria classified according to Gram's method: Gram-negative bacteria and Gram-positive bacteria. For example, Escherichia coli (E.coli) is a Gram-negative bacteria (it has a thin membrane which is difficult to penetrate and because of this it's often resistant to antibiotics). Some types of E. coli can produce a toxin named Shiga which is one of the most powerfull toxins that can cause intestinal infection. Stapyloccocus aureus (S.aureus) is a Gram-positive bacteria and it has a thick membrane. It may cause sepsis, toxic shock syndrome or meningitis (Schaalje, 2018; Stegarus and Lengyel, 2017).

According to a study conducted by World Health Organization, an estimated 180.000 deaths occur every year as a direct result of burn injuries, especially in lowand middle-income countries (Anenden, 2018). The purpose of researchers is to treat bacterial infections through the most innovative methods and a good solution is represented by biocompatible wound-dressing materials. 
Collagen (COLL) is the main protein in different tissues with many uses in medicine: wound care, tissue regeneration, bone grafts, cosmetic surgery and cardiac applications (Burdusel, 2016). Carboxymethylcellulose (CMC-Na) is derived from cellulose and it has unique properties such as biodegradability, non-toxicity and biocompatibility (Hollabaugh, 1945). Silver nanoparticles (AgNPs) provide a high level of biocompatibility, non-toxicity and biodegradability and can be considered as an effective antibacterial based wound dressing material for different kinds of wounds (Sathish, 2018).

Depending on the severity of the burns the material can be cross-linked with glutaraldehyde (GA) to incorporate a large amount of exudate in order to release nanoparticles faster. The aim of this study was to prepare and characterize wounddressing materials based on collagen, carboxymethylcellulose and silver nanoparticles for more fast and safe healing, considerably improving the quality of life.

The aim of this study was to develop and characterize collagen carboxymethylcellulose matrices with silver nanoparticles in order to be used in wound healing taking in consideration the collagen biocompatibility and the antimicrobial activity of silver nanoparticles.

\section{MATERIALS AND METHODS}

\section{Materials}

The type I fibrillar collagen gel having a concentration of $1 \%(\mathrm{w} / \mathrm{v})$ was extracted from calf hide using technology currently available at the Research-Development Textile Leather National Institute Division Leather and Footwear Research InstituteCollagen Department (Albu, 2011). CMC-Na having a concentration of $1 \%$ was purchased from Fluka. Silver nanoparticles were obtained in the National Centre for Micro and Nanomaterials (CNMN) from University Politehnica of Bucharest. Glutaraldehide was purchased from Merck (Germany) and collagenase was purchased from Sigma-Aldrich (China).

\section{Preparation of Wound-Dressing Materials}

The concentration of each collagen gel was adjusted from $2,26 \%$ to $1 \%$ and $7,4 \mathrm{pH}$ (the $\mathrm{pH}$ of the physiological medium in human body) using $1 \mathrm{M}$ sodium hydroxide. Silver nanoparticles (AgNPs) were in the form of colloidal solution because they offer better homogeneity and ensure their distribution inside the material for long-term antibacterial action. Silver nanoparticles (AgNPs) and carboxymethylcellulose (CMC$\mathrm{Na})$ were added to collagen gel $(\mathrm{w} / \mathrm{v})$ and then the samples were cross-linked with $0,025 \%$ glutaraldehyde (GA). All this informations are specified in Table 1.

Table 1. Names and composition of wound-dressing gels

\begin{tabular}{ccccc}
\hline Samples & Collagen, $\%$ & CMC-Na, $\%$ & AgNPs $(\mathrm{mL})$ & GA, $\%$ \\
\hline 1 & 1 & 1 & 10 & 0,025 \\
2 & 1 & 1 & 20 & 0,025 \\
3 & 1 & 1 & 10 & 0 \\
4 & 1 & 1 & 20 & 0 \\
5 & 1 & 1 & 0 & 0,025 \\
6 & 1 & 1 & 0 & 0 \\
\hline
\end{tabular}

https://doi.org/10.24264/icams-2018.I.18 
The gels for wound-dressing materials based on collagen, in order to be analyzed, were freeze-dried with Delta 2-24 LSC lyophilizer (Martin Christ, Germany) using a 48-hour lyophilization program and composites in spongious form were obtained.

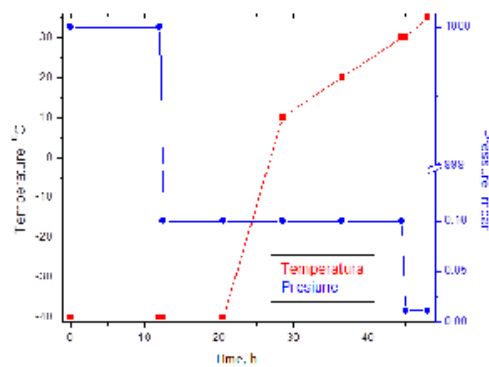

Figure 1. 24 hours lyophilization program used to obtain the matrices

\section{Methods}

FTIR-ATR Analysis

FT-IR spectral measurements were recorded using a Nicolet iN10 MX FT-IR spectrometer with MCT liquid nitrogen cooled detector in the measurement range 4000$400 \mathrm{~cm}^{-1}$. Spectral collection was made in reflection mode at $4 \mathrm{~cm}^{-1}$ resolution. For each spectrum, 32 scans were co-added and converted to absorbance using Ominc Picta software (Thermo Scientific).

\section{Enzymatic Degradation}

Enzymatic degradation was accomplished by immersing pieces of the lyophilized samples in a collagenase solution and monitoring the degradation over time. To monitor mass loss, samples were weighed at different time intervals, and calculated using the following equation:

$\% \mathrm{Weight}$ loss $=\mathrm{Wi}-\mathrm{Wt} / \mathrm{Wt} \times 100$

where W1 represents the initial mass and Wt represents the weight of the sample after the time interval $\mathrm{t}$.

\section{Scanning Electron Microscopy (SEM)}

The investigation of the samples was carried out with the aid of the Scanning Electron Microscope INSPECT F50 provided with a Field Emission Gun (FEG) with a resolution of $1,2 \mathrm{~nm}$ and a dispersive X-ray energy spectrometer with a resolution at $\mathrm{MnK}$ of $133 \mathrm{eV}$. For the proper conductivity of the samples, they were covered with gold for 60 seconds. 


\section{Antimicrobial Activity}

The control of antimicrobial activity was tested against E. coli (gram negative), $S$. aureus (gram positive) strains. Firstly, the gel for the lower layer without bacteria was prepared. $10 \mathrm{ml}$ of gel was put into each sterilized Petri dish and allow it to solidify. Secondly, gel for the upper layer was prepared and cooled down to $45^{\circ} \mathrm{C}$ in a water bath. Inoculation $150 \mathrm{ml}$ of gelose with $1 \mathrm{ml}$ of bacterial working solution $(1-5 \times 108 \mu \mathrm{g} / \mathrm{ml})$ was performed. The samples were placed on the surface of the nutrient medium and then incubated at $37^{\circ} \mathrm{C}$ between $18 \mathrm{~h}$ and $24 \mathrm{~h}$.

\section{RESULTS AND DISCUSSION}

After the lyophilization process, wound-dressing materials based on collagen (COL), carboxymethylcellulose (CMC-Na) and silver nanoparticles, cross-linked were obtained, having the structure presented in Figure 2.

1

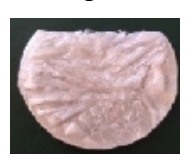

2

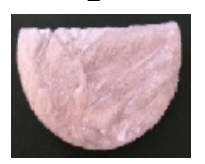

3

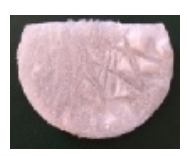

4

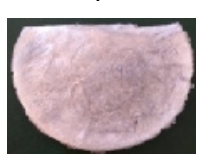

5

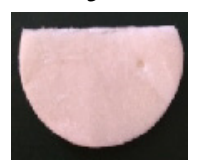

6

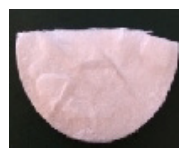

Figure 2. The aspect of the wound-dressing materials

All the samples from Table 1 were analyzed by FT-IR spectroscopy and the spectra are presented in Figure 3.

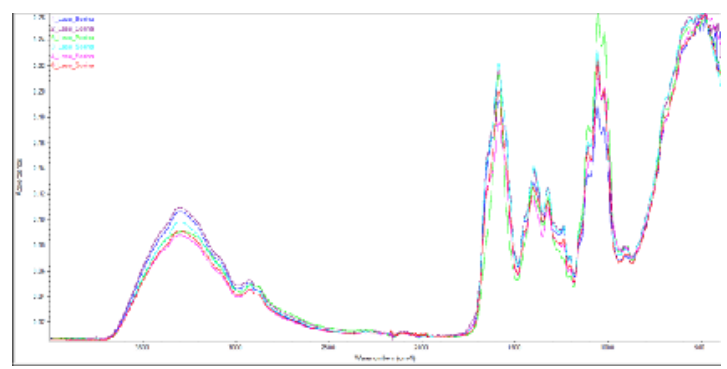

Figure 3. FT-IR spectra of all the samples

From Figure 3 it can be observed the typical amide bands of collagen i.e. $3303 \mathrm{~cm}-1$ and $2924 \mathrm{~cm}^{-1}$ for amide A and B respectively, $1630 \mathrm{~cm}^{-1}$ was ascribed to amide $\mathrm{I}(\mathrm{C}=\mathrm{O}$ stretching), $1544 \mathrm{~cm}^{-1}$ to amide II (N-H deformation) and $1238 \mathrm{~cm}^{-1}$ to amide III (N-H deformation) (Albu, 2011). The spectra, also showed, the characteristics peak of silver nanoparticles at 1625 and 1516, 1384 and $1047 \mathrm{~cm}^{-1}$. Figure 4 presents SEM images of all the samples. 

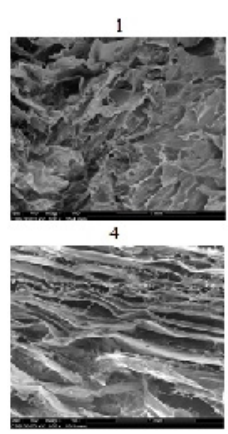
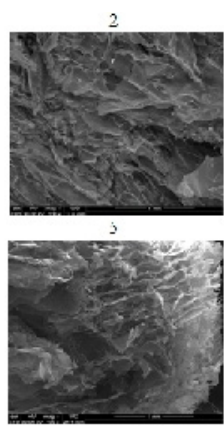
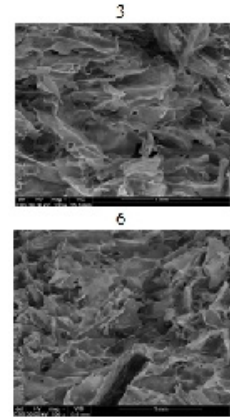

Figure 4. SEM images

In all the samples, the collagen structure is highly present. Samples 1 and 2 have a more disorganized structure and the sample 3 and 4 are cross-linked with glutaraldehyde (GA) and they have a more compact structure. Sample 5 and 6 presented the specific structure of collagen, fibrils with interconnected pores.

For enzymatic degradation tests, the samples were introduced into a collagenase solution (collagenase is an enzyme that breaks collagen structures) for 24 hours. The test results are presented in Figure 5.

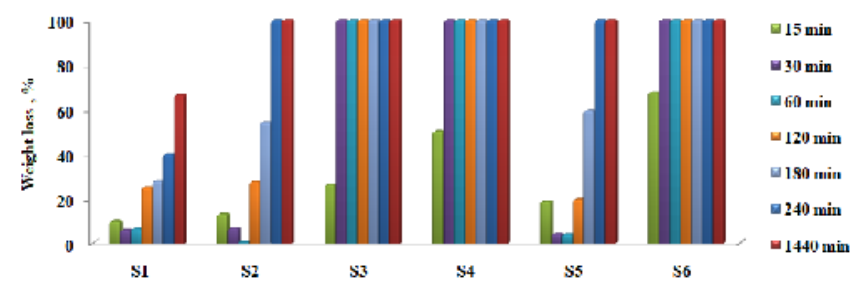

Figure 5. Weight loss of samples in collagenase solution over 24 hours

As it can be seen, the cross-linked samples 1, 2 and 5 showed a slower degradation compared to the rest of samples. The most stabile sample seems to be sample 1, with 10 $\mathrm{ml}$ AgNPs solution and glutaraldehyde, which 24 hours lost around 70\% from its weight.

In Figure 6 is presented the antimicrobial activity of all the sample, tested against Escherichia coli (gram negative), Staphyloccus aureus (gram positive).

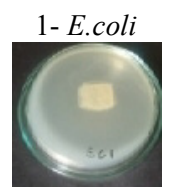

1-S. aureus

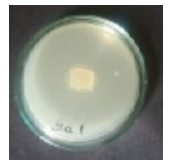

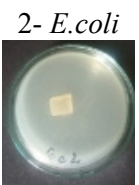

2- S. aureus

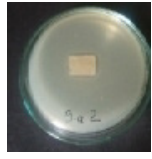

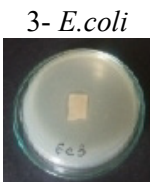

3-S. aureus

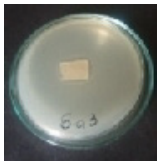

4- E.coli

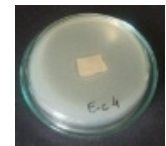

4- S. aureus

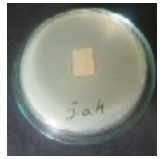

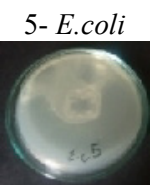

5- S. aureus

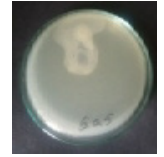

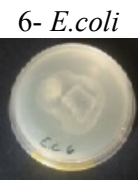

6- S. aureus

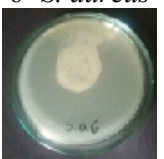

https://doi.org/10.24264/icams-2018.I.18 
Figure 6. Zones of inhibiton, against E. coli and S. aureus strains, of all the samples

From Figure 6 can be observed that all the samples 1-4, containing silver nanopaticles, and developed zone of inhibition against both $S$. aureus and E. coli strains. The result is considered to have a "satisfied effect" if no bacterial propagation is observed. Those probes do not allow the development of aerobic germs for the bacteria tested.

\section{CONCLUSIONS}

Type I collagen with carboxymethylcellulose and silver nanoparticles and their combinations were used in order to obtain matrices for tissue regeneration and antimicrobial activity. The combinations between components were highlighted by FTIR spectra where the specific peaks of both polymers were found. The most compact samples were the one cross-linked and the most stabile was sample 1 . The antimicrobial activity was proved by the zones of inhibition developed against $S$. aureus and E. coli strains. Thus, the samples are potentially novel candidates as scaffolds for tissue engineering applications.

\section{Acknowledgement}

This work was financially supported by NUCLEU project no. PN 18230202.

\section{REFERENCES}

Albu, M.G. (2011), Collagen Gels and Matrices for Biomedical Applications, Lambert Academic Publishing, Saarbrücken, 23-24.

Anenden, H. (2018), "Burns", World Health Organization, http://www.who.int/news-room/factsheets/detail/burns.

Burdusel, A.C. et al. (2016), "Development and Characterization of Collagen - Carboxymethylcellulose Materials for Lenses", Proceedings of The 6th International Conference on Advanced Materials and Systems, ICAMS 2016, https://doi.org/10.24264/icams-2016.II.4.

Church, D. et al. (2006), "Burn Wound Infections", Clinical Microbiology Reviews, 19(2), 403-434, https://doi.org/10.1128/CMR.19.2.403-434.2006.

Herndon, D. (2012), "Chapter 4: Prevention of Burn Injuries", Total burn care, Edinburgh: Saunders, p.46, ISBN 978-1-4377-2786-9.

Hollabaugh, C.B., Burt, H.L. and Walsh, A.P. (1945), "Carboxymethylcellulose. Uses and applications", Industrial and Engineering Chemistry, 37(10), 943-947, https://doi.org/10.1021/ie50430a015.

Kumar, S.S.D. et al. (2018), "Recent advances on silver nanoparticle and biopolymer-based biomaterials for wound healing applications", International Journal of Biological Macromolecules, 115, 165-175, https://doi.org/10.1016/j.ijbiomac.2018.04.003.

Schaalje, J. (2018), "Medical Terminology: Gram-Positive vs. Gram-Negative Bacteria”, American College of Healthcare Sciences (http://info.achs.edu/blog/bid/282924/medical-terminology-gram-positive-vs-gramnegative-bacteria).

Stegarus, D.I. and Lengyel, E. (2017), "The antimicrobial effect of essential oils upon certain nosocomial bacteria”, 17th International Multidisciplinary Scientific GeoConference (SGEM 2017), 17, 61, 1089 1096. 